\title{
As paixões do julgador nas sentenças condenatórias de roubo: apresentação da pesquisa
}

Sergio Gardenghi SUIAMA (USP)

RESUMO: O artigo apresenta pesquisa de iniciação científica cujo objeto é a análise do percurso de sentido de sentenças condenatórias de roubo. O interesse do autor é estudar as formações ideológicas e as paixões do destinador julgador. Para tanto, quer analisar o percurso do julgamento, tendo como método a semiótica greimasiana.

PALAVRAS-CHAVE: semiótica jurídica; narratividade; ideologia; paixões.

ABSTRACT: The aim of this article is to present a preliminary investigation which object is the analysis of the "path of meaning" in robbery final sentences. The intention is to study the ideological constitution and the passions contained in the senderarbitrator's speach. Furthermore, the author intends to analyze the path of the sanction, using the method given by Greimas' semiotic criteria.

KEYWORDS: legal semiotic; narrativity; ideology; passions. 


\section{Apresentação geral.}

A recém inaugurada pesquisa de iniciação científica pretende identificar o percurso gerativo do sentido de sentenças condenatórias em processos de roubo ${ }^{1}$. Mais especificamente, ela busca localizar as paixões e as formações ideológicas contidas em certa formação discursiva hoje majoritária nas decisões criminais proferidas pelo Poder Judiciário do Estado de São Paulo. Refiro-me à postura ilegal e acrítica de juízes criminais que, ao condenarem réus acusados do crime de roubo, fixam regime prisional mais severo do que aquele permitido pela lei. Para tanto, tais juízes lançam mão de uma espécie de "fórmula retórica", sintetizada na seguinte frase: "o roubo é crime grave que ameaça e atemoriza a população pacata e ordeira e por si só revela a periculosidade e o desvio de personalidade de seus agentes: daí a necessidade de punição exemplar e severa para quem o comete".

É necessário dizer algumas palavras a respeito do campo discursivo ao qual pertence o discurso investigado, para melhor precisar o objeto da pesquisa. O sistema jurídico está organizado em torno de normas que estabelecem competências e proíbem, ordenam ou autorizam comportamentos. Uma dessas normas, contida na Constituição brasileira, proíbe que o Estado imponha uma sanção penal a alguém, sem que instaure, previamente, um processo acusatório, desenvolvido perante um juiz ${ }^{2}$. Esse processo é iniciado, em geral, por um membro do Ministério Público. O réu - isto é, aquele a quem se acusa ter cometido uma ação criminosa - é chamado a apresentar sua versão sobre os fatos, sendo-lhe assegurado o direito de mentir ou de permanecer calado. Caso não possua advogado particular, um defensor público fará sua defesa. Durante o processo, as partes podem produzir provas. Ao final, pedem, cada qual, a condenação ou a absolvição do réu, apresentando os argumentos fáticos e jurídicos que dão suporte ao pedido. O juiz, então, deve pronunciar uma sentença, na qual resumirá os argumentos lançados pela acusação e pela defesa, e decidirá, fundamentadamente, pela condenação ou absolvição do réu. Na hipótese de condenação, o juiz deverá, "atendendo à culpabilidade, aos antecedentes, à conduta social, à personalidade do agente, aos motivos, às circunstâncias e conseqüências do crime, bem como ao comportamento da vítima" fixar, "conforme seja necessário e suficiente para reprovação e prevenção do crime": a) as penas aplicáveis dentre as cominadas (prisão, multa, prestação de serviços à comunidade etc.); b) a quantidade de pena aplicável, dentro dos limites previstos; e c) o regime inicial de cumprimento da pena privativa de liberdade ${ }^{3}$.

Em nosso sistema jurídico, o regime inicial de cumprimento da pena de prisão pode ser "fechado", "semi-aberto" ou "aberto". O regime fechado, mais severo, é cumprido em presídios. O semi-aberto é cumprido em colônias penais, e é menos rigoroso porque admite que o preso possa exercer atividades de trabalho externas, freqüientar cursos e eventualmente passar feriados com a família. A definição do regime prisional é feita, em princípio, pelo próprio Código Penal. Condenados primários a penas inferiores a oito anos tem, em tese, o direito a cumprir a pena em regime inicial aberto ou semi-aberto. A imposição do regime fechado para eles é admitida desde que o juiz, na expressão do Supremo Tribunal Federal ${ }^{4}$, ofereça "motivação idônea", ou seja, 
analise, no caso concreto, a culpabilidade, os antecedentes, a conduta social do réu, os motivos, as circunstâncias e conseqüências do crime, e o comportamento da vítima.

Pois bem. Durante os quase quatro anos em que trabalhei como defensor público criminal, pude observar que os juízes estaduais de São Paulo não seguem, nas sentenças condenatórias em crimes de roubo, a orientação dada pela lei e pelo Supremo Tribunal Federal. A percepção acaba de ser confirmada pela publicação do relatório Decisões Judiciais nos Crimes de Roubo em São Paulo: a Lei, o Direito e a Ideologia (IBCCrim 2005). Pesquisadores do Instituto Brasileiro de Ciências Criminais e do Instituto de Defesa do Direito de Defesa analisaram 605 processos de roubo com sentença condenatória em São Paulo, julgados entre $1^{\circ}$ de janeiro de 1999 e 31 de dezembro de 2000. Ao final, concluíram que em $82,34 \%$ dos casos os réus foram condenados a regime prisional mais restritivo do que o previsto em lei, ainda que primários e tendo obtido aplicação da pena base no mínimo legal. A fundamentar as decisões, encontram-se motivações de caráter extrajurídico e cunho ideológico, comuns às teses encontradas no senso comum sobre a criminalidade. "Os argumentos mobilizados em tais decisões coadunam e talvez constituam de per si o que tem se propagado por meio de verdadeiras redes sociotécnicas formadas pelo campo midiático, burocrático, por vezes acadêmico, dando coro à retórica dos movimentos ultraconservadores, esvaziada de conteúdo e de valor científico ou quiçá de amparo no real. (...) Por certo o caráter ideológico está presente na atuação dos juízes, retratando sua filiação política e ideológica, sendo difícil sua dissociação, embora desejável em certa medida num regime democrático. Em matéria penal, no entanto, esta filiação tem se traduzido em medidas extremamente repressivas e anacrônicas, revelando sua atuação como à margem da Lei e de um direito penal moderno e racional" (IBCCrim 2005: 58-59).

Transcrevo, abaixo, trechos de sentenças recolhidas, para que o leitor possa ver por si próprio do que estamos falando:

"Correto o regime determinado. O roubo é expressão delituosa que envergonha a Nação, intranqüiliza a sociedade, mantendo-a refém dessa espécie de marginal."

"Por fim, no que concerne ao regime prisional, o recurso também não está em caso de ser provido. Nem seria necessário ressaltar que o delito de roubo, à mão armada, é de gravidade evidente e notória. De igual modo, também nem precisaria ser referido que a segurança pessoal e coletiva, máxime nos grandes centros, não pode ser negligenciada, deixando pessoas inocentes e cumpridoras de seus deveres sociais, à mercê de delinqüentes e desocupados. Tão só por isso, bem de ver-se, em casos tais, impõe-se o regime fechado.

No caso presente, cuida-se de assalto em plena via pública, à mão armada, com a subtração de veículo das vítimas, o que revela temibilidade e periculosidade irretorquíveis, na medida em que a ousadia dos assaltos demonstra a certeza da impunidade. De tal sorte que, em hipóteses tais, o único regime capaz 
de assegurar um mínimo de segurança às pessoas honestas e cumpridores de seus deveres sociais, bem como o único apto a atender o princípio da necessidade e suficiência da resposta penal, com vista à prevenção e reprovação do crime, nos termos do artigo 59, III, do CP, é o fechado"6.

"Em síntese, certo que a determinação do regime prisional não é mero consectário da quantidade da pena reclusiva imposta, devendo ser levados em consideração os fatores contemplados no art. 59 do Código Penal, força é convir em que o agente de roubo sujeita-se ao regime fechado, porque $a$ autoria de crime dessa natureza põe em evidência, 'personalidade' marcadamente defeituosa".

"O regime fechado é mantido. Trata-se o roubo de delito violento que desassossega a população ordeira, deixando-a em sobressalto e, infelizmente, vem aumentando sua prática, principalmente nas grandes cidades. E esse estado de coisa há de ser coibido pelo Judiciário, o qual, ao impor regime mais gravoso, não só retirará o agente perigoso do convívio social, bem como evitará que ele continue a exercer suas atividades ilícitas. Por isso, o roubador merece, inegavelmente, cumprir sua expiação em regime fechado, sendo obrigatoriamente submetido a exame de cessação de perigosidade para eventual progressão" $"$.

\section{Posição da sentença criminal na semiótica greimasiana.}

No modelo teórico adotado - a semiótica francesa de matriz greimasiana coube ao próprio Greimas e a Éric Landowski (Greimas 1976) iniciar a investigação deste objeto semiótico chamado "discurso jurídico". No artigo "Análise semiótica de um discurso jurídico", os autores apresentaram quatro idéias fundamentais para a presente pesquisa: a) o discurso jurídico é um discurso (isto é, a manifestação sintagmática e linear da língua, passível, como tal, de descrição pela semiótica), dotado de uma organização específica das unidades que o constituem; b) tal discurso possui uma gramática, uma semântica e uma narratividade; c) ele se desenvolve sobre uma dupla isotopia: o discurso legislativo, composto por atos performativos e normativos que instituem regras prescritivas e proibitivas; e o discurso referencial, que instaura seres e coisas no mundo construído como isomórfico à "realidade do mundo" logicamente anterior ao discurso legislativo; d) o sistema jurídico é atualizado por discursos jurídicos constantemente renovados que se manifestam em duas espécies de práticas jurídicas: a produção jurídica (legislativa) e o que Greimas e Landowski chamaram de "procedimento recorrente de verificação da validade da linguagem jurídica instituída".

Os autores descrevem assim esse procedimento:

“A partir d'un nombre indéfini de 'faits' e d'événements' qui, dès qu'on en parle, paraissent susceptibles de faire partie, en tant qu'énoncés descriptifs, du 
niveau référentiel du langage juridique, mais qui n'en restent pas moin agrammaticaux, la pratique de la jurisprudence consiste à vérifier leur conformité aux énoncés que peut produire, grammaticalement, le discours législatif. Autrement dit, une fois acquise la sémanticité du fait relaté, la vérification se fait par la traduction d'un énoncé non juridique en un énoncé conforme aux règles de construction des énoncés juridiques, et ceci afin de montrer que, parmi tous les énoncés qu'est capable d'engendrer la grammaire juridique, il existe au moins un énoncé conforme à celui qui provient de la traduction de l'énoncé non juridique" (Greimas 1976: 92).

Trata-se, como se vê, daquilo que a linguagem jurídica chama de "aplicação do direito", isto é, a subsunção de um "fato" (o "discurso referencial"), a uma norma (o "discurso legislativo"), feita por enunciadores - os ditos "operadores do direito" dotados de um saber fazer específico, objeto de controle social.

O corpus estudado por Greimas e Landowski era a lei francesa das sociedades comerciais. Talvez por esse motivo, não tenham cuidado eles de examinar mais detalhadamente a atividade de verificação da validade da linguagem jurídica. $\mathrm{O}$ exame, todavia, é a meu ver muito relevante, pois, a título de hipóteses desta pesquisa, entendo que: a) a prática jurídica não se limita a controlar a validade de enunciados legislativos permanentes, mas sim atualizar esses enunciados, reinterpretando-os; b) a atividade do destinador atualizador possui natureza axiológica, refletindo a escolha de valores socialmente postos; c) como todo discurso, também o discurso jurídico é a materialização de formações ideológicas (Fiorin 2003: 41), reproduzidas pelo enunciador.

Em trabalho posterior, Landowski (1992) voltou a abordar o tema e forneceu mais alguns elementos importantes para a análise do discurso jurídico. Partindo da separação entre normas primárias e secundárias feita por Hart, Landowski distinguiu duas funções do "destinador axiológico" (a instância que tem como papel "enunciar no primeiro grau as 'regras da vida em sociedade', de caráter obrigatório para os sujeitos, que, tomados em conjunto, constituem o que chamamos desta vez e por todas, direito"): a formulação de enunciados a priori, estatuindo sobre o valor de elementos ainda virtuais; e de enunciados a posteriori, nos quais o "destinador judicador" sanciona positiva ou negativamente o sujeito do agir. A primeira função é exercida pelo ator "legislador"; a segunda, pelo ator "juiz".

A sentença penal é, nessa perspectiva, um texto produzido por alguém que se enuncia investido de uma função actancial específica: a de destinador julgador. Como se sabe, no percurso do julgamento, coube a este actante a execução de duas espécies de sanção: a sanção cognitiva, na qual o destinador julgador transforma o "fazer" do sujeito em um "ser", objeto de cognição e interpretação, e a sanção pragmática, de retribuição ao sujeito da performance, sob a forma de recompensa ou punição.

Essas duas etapas do percurso narrativo estão reguladas pela gramática do direito brasileiro no art. 381 do Código de Processo Penal. Vale a pena examiná-lo em perspectiva semiótica: 
Art. 381. A sentença conterá:

I - os nomes das partes ou, quando não possível, as indicações necessárias para identificá-las;

II - a exposição sucinta da acusação e da defesa;

III - a indicação dos motivos de fato e de direito em que se fundar a decisão;

IV - a indicação dos artigos de lei aplicados;

V - o dispositivo;

VI - a data e a assinatura do juiz.

As "partes" - autor ${ }^{9}$ e réu - são os atores que figuram na superfície discursiva sentença. Convém lembrar que, para Greimas e Courtés, "ator" é a "unidade lexical, de tipo nominal, que, inscrita no discurso, é suscetível de receber, no momento de sua manifestação, investimentos de sintaxe discursiva de superfície e de semântica discursiva" (Greimas e Courtés 1993: 7). Na sentença condenatória, como veremos mais adiante, o ator "réu" assume a clara função de anti-sujeito do discurso.

Após apresentar os atores, o enunciador "juiz" deverá, de acordo com o inciso II, resumir (e interpretar) o "fazer persuasivo" dos atores "Ministério Público" e "advogado", que haviam, na etapa anterior do processo judicial, elaborado seus textos, com o fim de influir no juízo de veridicção realizado pelo destinador julgador ${ }^{10}$.

Os incisos III e IV do artigo tratam, precisamente, do juízo de veridicção feito pelo destinador julgador. Nele, o enunciador qualificará os discursos enunciados pelas partes (e também pelo réu, em seu interrogatório judicial) de verdadeiros, falsos, mentirosos $^{11}$ ou secretos, as modalidades do juízo cognitivo.

A referência aos "motivos de fato e de direito" e aos "artigos de lei aplicados", feita pelo texto legal, justifica-se porque, como já visto, o discurso jurídico se desenvolve sobre uma dupla isotopia: o discurso legislativo, composto por atos performativos e normativos que instituem regras prescritivas e proibitivas (os tais "motivos de direito"); e o discurso referencial, que instaura seres e coisas no mundo construído como isomórfico à "realidade do mundo" logicamente anterior ao discurso legislativo (os "motivos de fato"). Convém lembrar que a semiótica não estuda ações propriamente ditas, mas ações "en papier", isto é, descrições de ações (Greimas e Courtés, 1993: 8). O que o juiz faz, portanto, é selecionar, no descontínuo dos autos judiciais, elementos já gramaticalizados (“o que não está nos autos, não está no mundo"!), atribuindo a eles um significado jurídico conforme ao discurso legislativo previamente enunciado:

Autrement dit, une fois acquise la sémanticité du fait relaté, la vérification se fait par la traduction d'un enoncé non juridique en un énoncé conforme aux règles de construction des énoncés juridiques, et ceci afin de montrer que, parmi tous les énoncés qu'est capable d'engendrer la grammaire juridique, il existe au moins un énoncé conforme à celui qui provient de la traduction de l'énoncé non juridique. (Greimas 1976 : 92). 
Na sentença criminal, um enunciado não-jurídico como "o mano tava na nóia e catou o carro do bacana" será traduzido em uma frase gramática e semanticamente adequada ao discurso jurídico, do tipo "restou provado nos autos que o réu subtraiu para si, mediante grave ameaça exercida com o emprego de arma de fogo, o automóvel da vítima".

Como toda atividade de tradução, também a passagem de um enunciado nãojurídico a outro jurídico importa na produção de um novo texto, por enunciador diverso daquele a quem se atribui a autoria do enunciado original. Na produção do texto "sentença", o enunciador juiz sofre restrições de natureza semântica (pois não está autorizado a utilizar lexemas impróprios ao discurso jurídico), sintática (porque o citado art. 381 do Código de Processo Penal prescreve uma determinada organização discursiva) e enunciativa (em razão do dever de "imparcialidade" que lhe é prescrito).

Antes de abordar a segunda etapa do percurso da sanção, gostaria de me deter um pouco mais na imparcialidade do julgador como restrição formal à enunciação do texto em questão.

Desde as revoluções liberais burguesas, a garantia da imparcialidade do julgador integra o rol de direitos da pessoa humana. Ela vem declarada em quase todos os documentos internacionais de proteção, a começar pela própria Declaração Universal dos Direitos do Homem ${ }^{12}$. Do ponto de vista semiótico, como bem observaram Rüsche, Teixeira e Magri, trata-se de uma modalização do sujeito do fazer "juiz" por um dever ser (2003: 335), semanticamente definido como "julgar sem paixão", "se abster de tomar partido ao julgar".

Na superfície textual, uma das estratégias adotadas pelo enunciador "juiz" para marcar a observância da regra da imparcialidade é a predominância de debreagens actanciais, espaciais e temporais enuncivas ${ }^{13}$. O anti-sujeito "réu" - cujo percurso narrativo será objeto da sanção negativa - é um "ele", a quem se atribui a prática de uma ação criminosa ocorrida fora do espaço e do tempo da enunciação. Daí o emprego, na sentença condenatória, do momento de referência pretérito em relação ao tempo da enunciação, e do "alhures" como espaço onde se desenvolveu a ação narrada (a qual será adjetivada de "criminosa"). Daí, também, o uso dominante, pelo enunciador, do discurso indireto referencial, na narração do "fato" objeto do processo.

Como já foi dito, um dos objetivos da pesquisa é identificar os "rastros da paixão" - e da ideologia - deixados pelo enunciador de sentenças condenatórias constitutivas do corpus analisado. Pretendo, com isso, colocar entre parêntesis as bases fracas que sustentam a ideologia legalista do sistema judicial brasileiro. A hipótese inicial de trabalho é que tais rastros podem ser encontrados nos níveis discursivo e narrativo do percurso gerativo de sentido das sentenças condenatórias. No nível narrativo, penso que talvez seja possível localizar - especialmente na dimensão pragmática da sanção - os estados de alma (anteriores, concomitantes ou posteriores) que levaram o destinador julgador a colocar o anti-sujeito em disjunção com o objetovalor "liberdade". Para tanto, será preciso reconstruir os programas narrativos contidos na sentença condenatória e verificar como eles se integram no texto. Isto será feito no curso da pesquisa. Por ora, e para concluir, gostaria de abordar a questão da sanção pragmática, no discurso do destinador julgador criminal. 
Ela vem indicada no inciso V do citado art. 381 do Código de Processo Penal, sob a denominação "dispositivo". Na semiótica greimasiana, como é sabido, a sanção pragmática será positiva quando o julgador, reconhecendo a conformidade do sujeito do fazer com o sistema axiológico dado pelo destinador manipulador, atribui-lhe uma recompensa. E será negativa em duas hipóteses: a) quando o sujeito do fazer não cumpre o contrato fiduciário celebrado com o destinador manipulador; b) quando é sancionado por um destinador-julgador que encarne valores contrários ou contraditórios aos do destinador-manipulador; é o que acontece na punição do anti-sujeito (Barros 2001: 41).

Numa primeira leitura, identifiquei o destinador-julgador ao sujeito do fazer, responsável por colocar em conjunção ou disjunção o sujeito de estado (e sujeito da ação pretérita, alvo da sanção cognitiva) com o objeto de valor. Se a leitura estiver correta, talvez seja possível dizer que, nas sentenças condenatórias, o destinador julgador é o sujeito do fazer responsável por colocar o sujeito de estado "réu" em disjunção com o objeto de valor "liberdade". Seria interessante, também, apurar se, no discurso contido no corpus há a enunciação de estados de alma atribuíveis ao julgador, anteriores ou posteriores à ação sancionadora.

São essas as linhas gerais da pesquisa que se inicia.

\section{REFERÊNCIAS BIBLIOGRÁFICAS}

BARROS, D. L. P. de (2001). Teoria do Discurso: fundamentos semióticos. São Paulo, Atual.

FIORIN, J. L. (2002). As Astúcias da Enunciação: as categorias de pessoa, espaço e tempo. São Paulo, Ática. (2002a). Elementos de Análise do Discurso, São Paulo, Contexto. (2003). Linguagem e Ideologia. São Paulo, Ática.

GREIMAS, A. J. (1976) Sémiotique et Sciences Sociales. Paris, Seuil.

GREIMAS, A. J. e COURTÉS, J. (1993). Sémiotique: dictionnaire raisonné de la théorie du langage. Paris, Hachette.

GREIMAS, A. J. e FONTANILlE, J. (1993). Semiótica das Paixões: dos estados de coisas aos estados de alma. São Paulo, Ática.

IBCCRIM e IDDD (2005). Decisões Judiciais nos crimes de roubo em São Paulo: a lei, o direito e a ideologia. São Paulo, IBCCrim.

LANDOWSKI, E. (1992). A Sociedade Refletida: ensaios de sociossemiótica. São Paulo, Educ/Pontes.

(2002). Presenças do Outro: ensaios de sociossemiótica. São Paulo,

Perspectiva.

MAINGUENEAU, D. (2005). Gênese dos Discursos. São Paulo, Criar.

RÜSCHE, A.; TEIXEIRA, J.; MAGRI, W. (2003), "O juiz, a imparcialidade e a semiótica das paixões" in Cadernos de Discussão do Centro de Pesquisas Sociossemióticas. São Paulo, PUC-SP/FFLCH-USP/CNRS-Paris.

SAUSSURE, F. de (s.d.). Curso de Linguística Geral. São Paulo, Cultrix.

TATIT, L. (2001). Análise Semiótica através das Letras. São Paulo, Ateliê. 


\section{Como citar este artigo:}

SUIAMA, Sergio Gardenghi. As paixões do julgador nas sentenças condenatórias de roubo: apresentação da pesquisa. Estudos Semióticos, Número 2, São Paulo, 2006. Disponível em <www.fflch.usp.br/dl/semiotica/es>. Acesso em "dia/mês/ano".

${ }^{1} \mathrm{O}$ crime de roubo está assim definido no art. 157 do Código Penal:

Art. 157 - Subtrair coisa móvel alheia, para si ou para outrem, mediante grave ameaça ou violência a pessoa, ou depois de havê-la, por qualquer meio, reduzido à impossibilidade de resistência:

Pena - reclusão, de quatro a dez anos, e multa.

$\S 1^{\circ}$ - Na mesma pena incorre quem, logo depois de subtraída a coisa, emprega violência contra pessoa ou grave ameaça, a fim de assegurar a impunidade do crime ou a detenção da coisa para si ou para terceiro.

$\S 2^{\circ}$ - A pena aumenta-se de um terço até metade:

I - se a violência ou ameaça é exercida com emprego de arma;

II - se há o concurso de duas ou mais pessoas;

III - se a vítima está em serviço de transporte de valores e o agente conhece tal circunstância.

IV - se a subtração for de veículo automotor que venha a ser transportado para outro Estado ou para o exterior;

$\mathrm{V}$ - se o agente mantém a vítima em seu poder, restringindo sua liberdade.

$\S 3^{\circ} \mathrm{Se}$ da violência resulta lesão corporal grave, a pena é de reclusão, de sete a quinze anos, além da multa; se resulta morte, a reclusão é de vinte a trinta anos, sem prejuízo da multa.

${ }^{2}$ Art. $5^{\circ}$, inciso LIV, da Constituição: "ninguém será privado da liberdade ou de seus bens sem o devido processo legal".

${ }^{3}$ Código Penal, art. 59.

${ }^{4}$ Súmula 719 do STF: "A imposição do regime de cumprimento mais severo do que a pena aplicada permitir exige motivação idônea". A Súmula 718 esclarece que "a opinião do julgador sobre a gravidade em abstrato do crime não constitui motivação idônea para a imposição de regime mais severo do que o permitido segundo a pena aplicada". Súmula é uma consolidação de decisões reiteradas no mesmo sentido.

${ }^{5}$ TACRIM-SP, Apelação Criminal n. ${ }^{\circ}$ 1.203.559/2.

${ }^{6}$ TACRIM-SP, Apelação Criminal n. ${ }^{\circ} 1.191 .585 / 7$. 
${ }^{7} 2^{\mathrm{a}}$ Vara Criminal de Osasco, autos n. ${ }^{\circ}$ 476/99.

${ }^{8}$ TACRIM-SP, Apelação Criminal n. $^{\circ} 1.189 .463 / 5$.

${ }^{9}$ Em geral, como dissemos, o Ministério Público. Em alguns crimes, o processo penal é iniciado exclusiva ou subsidiariamente pela vítima.

${ }^{10}$ Que, na perspectiva das partes, é o destinatário do fazer crer.

${ }^{11}$ Por exemplo: "o réu negou a autoria criminosa. Todavia, a vítima foi categórica ao reconhecê-lo como o autor do delito".

${ }^{12} \mathrm{O}$ artigo $10^{\circ}$ da Declaração prescreve a imparcialidade nos seguintes termos: "Toda pessoa tem direito, em plena igualdade, a uma audiência justa e pública por parte de um tribunal independente e imparcial, para decidir de seus direitos e deveres ou do fundamento de qualquer acusação criminal contra ele".

${ }^{13} \mathrm{Na}$ expressão de Fiorin (2002: 44-45), a debreagem enunciva (por oposição à debreagem enunciativa) "é aquela em que se instauram no enunciado os actantes do enunciado (ele), o espaço do enunciado (algures) e o tempo do enunciado (então)". Para o mesmo autor, "a eliminação das marcas de enunciação do texto, ou seja, da enunciação enunciada, fazendo que o discurso se construa apenas com enunciado enunciado, produz efeitos de sentido de objetividade". 